\title{
CONHECIMENTO DE ESTUDANTES \\ DE ENFERMAGEM SOBRE PARADA \\ CARDIORRESPIRATÓRIA: ESTUDO TRANSVERSAL
}

\author{
KNOWLEDGE OF NURSING STUDENTS \\ ON CARDIORESPIRATORY ARREST: \\ A CROSS-SECTIONAL STUDY
}

\section{CONOCIMIENTTO DE LOS ESTUDIANTES DE ENFERMERÍA SOBRE PARADA CARDIORRESPIRATORIA: ESTUDIO TRANSVERSAL}

\author{
Felipe Pereira Nunes ${ }^{1}$ \\ Keylla Talitha Fernandes Barbosa ${ }^{2}$ \\ Fabiana Maria Rodrigues Lopes de Oliveira ${ }^{3}$ \\ Natalia Pessoa da Rocha Leal ${ }^{4}$ \\ Vinícius de Morais Santos \\ Lucianna Jéssica Araújo da Silva ${ }^{6}$ \\ Júlia Beatriz Lacet Nóbrega da Silva ${ }^{7}$
}

\begin{abstract}
Como citar este artigo: Nunes FP, Barbosa KTF, Oliveira FMRL, Leal NPR, Santos VM, Silva LJA, et al. Conhecimento de estudantes de enfermagem sobre parada cardiorrespiratória: estudo transversal. Rev baiana enferm. 2021;35:e43160.

Objetivo: avaliar o conhecimento de estudantes de enfermagem sobre o atendimento ao paciente em parada cardiorrespiratória. Método: estudo transversal com abordagem quantitativa, realizado com 136 acadêmicos do curso de enfermagem de uma instituição de ensino superior. Os dados foram coletados por meio de instrumento semiestruturado. A análise efetivou-se por meio da estatística descritiva e inferencial. Resultados: os discentes que se autoavaliaram positivamente, mostraram um bom nível de conhecimento sobre a temática $(\mathrm{r}=0,29 ; \mathrm{p}=0,001)$, assim como aqueles que haviam cursado a disciplina de primeiros socorros em períodos anteriores $(\mathrm{p}=0,012)$. As questões nas quais obtiveram erro foram aquelas a respeito das vias de administração da droga e suporte ventilatório em pacientes não intubados. Conclusão: os discentes de enfermagem demonstraram um nível adequado de compreensão dos protocolos sobre o atendimento ao paciente em parada cardiorrespiratória e possuíam arcabouço teórico obtido na disciplina de primeiros socorros, bem como em cursos de aperfeiçoamento.
\end{abstract}

Descritores: Enfermagem. Estudantes de Enfermagem. Conhecimento. Parada Cardíaca.

Objective: to evaluate the knowledge of nursing students about the care of patients in cardiorespiratory arrest. Method: cross-sectional study with quantitative approach, conducted with 136 nursing students from a bigher education institution. Data were collected using a semi-structured instrument. The analysis was performed through descriptive

\footnotetext{
Enfermeiro. Pesquisador Independente. João Pessoa, Paraíba, Brasil. http://orcid.org/0000-000 I-9302-0438.

Enfermeira. Doutora em Enfermagem. Docente do Centro Universitário de João Pessoa. João Pessoa, Paraíba, Brasil. keyllafernandes@gmail.com. http://orcid. org/0000-000 I-6399-002X

Enfermeira. Doutora em Enfermagem. Docente do Centro Universitário de João Pessoa. João Pessoa, Paraíba, Brasil. http://orcid.org/0000-0002-5966-232X.

Enfermeira. Mestre em Enfermagem. Docente do Centro Universitário de João Pessoa. João Pessoa, Paraíba, Brasil. http://orcid.org/0000-000 I-6404-5580.

Enfermeiro. Pesquisador Independente. João Pessoa, Paraíba, Brasil. http://orcid.org/0000-0002-6765-52। 8

Enfermeira. Pesquisador Independente. João Pessoa, Paraíba, Brasil. http://orcid.org/0000-000 I-9509-0640.

Enfermeira. Pesquisador Independente. João Pessoa, Paraíba, Brasil. http://orcid.org/0000-0002-659|-259|
} 
and inferential statistics. Results: the students who positively evaluated themselves showed a good level of knowledge about the theme ( $r=0.29 ; p=0.001)$, as well as those who had attended the first aid course in previous periods $(p=0.012)$. The questions they made mistakes were those regarding the routes of administration of the drug and ventilatory support in non-intubated patients. Conclusion: the nursing students demonstrated an adequate level of understanding of the protocols on the care of patients in cardiorespiratory arrest and had a theoretical framework obtained in the discipline of first aid, as well as in improvement courses.

Descriptors: Nursing. Nursing Students. Knowledge. Cardiac Arrest.

Objetivo: evaluar el conocimiento de los estudiantes de enfermería sobre el cuidado de los pacientes en parada cardiorrespiratoria. Método: estudio transversal con abordaje cuantitativo, realizado con 136 estudiantes de enfermería de una institución de educación superior. Los datos fueron recogidos por medio de un instrumento semiestructurado. El análisis se realizó a través de estadística descriptiva e inferencial. Resultados: los estudiantes que se evaluaron positivamente mostraron un buen nivel de conocimiento sobre el tema ( $r=0,29 ; p=0,001)$, asi como los que habian asistido al curso de primeros auxilios en periodos anteriores ( $p=0,012)$. Las preguntas en las que obtuvieron error fueron las relativas a las vías de administración del fármaco y soporte ventilatorio en pacientes no intubados. Conclusión: los estudiantes de enfermería demostraron un adecuado nivel de comprensión de los protocolos sobre el cuidado de pacientes en parada cardiorrespiratoria y contaron con un marco teórico obtenido en la disciplina de primeros auxilios, así como en cursos de perfeccionamiento.

Descriptores: Enfermería. Estudiantes de Enfermería. Conocimiento. Paro cardiaco.

\section{Introdução}

No Brasil, ocorrem por volta de 200 mil casos de Parada Cardiorrespiratória (PCR) por ano. Destas, 50\% acontecem no âmbito intra-hospitalar ${ }^{(1)}$. Além disso, são consideradas as situações de maior emergência atendidas no ambiente pré-hospitalar. Deve-se considerar, entretanto, que perto de $95 \%$ dos pacientes falecem antes de chegarem ao hospital ${ }^{(2)}$.

A PCR é definida como a interrupção dos batimentos cardíacos, das trocas gasosas e da perda do nível de consciência, podendo ser evidenciada por meio da ausência de pulso carotídeo, de incursões respiratórias assim como da presença de respiração agônica. Ademais, verifica-se alterações nos ritmos cardíacos, a exemplo de Assistolia, Atividade Elétrica sem pulso (AESP), Fibrilação Ventricular (FV) e Taquicardia Ventricular sem pulso (TVSP), os quais podem gerar danos cerebrais irreversíveis e, em alguns casos, óbito $^{(3)}$.

Logo, o reconhecimento precoce, por meio da vigilância contínua dos pacientes, busca identificar rapidamente o evento, permitindo a realização das manobras corretas, conforme os protocolos internacionais, o que reduz a taxa de mortalidade frente à PCR. Por meio das manobras da ressuscitação cardiopulmonar (RCP) é possível manter a circulação corpórea, garantindo a oxigenação dos órgãos vitais. Ao confirmar a parada, por meio da verificação da ausência de pulso central, o profissional deve iniciar imediatamente a assistência, conforme preconizado no protocolo de $\mathrm{RCP}^{(2)}$.

Para tanto, a adoção de protocolos internacionais deve ser instituída, a fim de aumentar a chance de sobrevida do paciente. Entre esses, destacam-se as diretrizes propostas pela American Heart Association, em que as atualizações periódicas baseiam-se em processo internacional de validação de evidências, envolvendo diversos revisores da área de saúde de diferentes países. Tal protocolo existe para que os profissionais tenham mais segurança e respaldo ao longo da luta pela vida e, dessa forma, possam garantir uma assistência mais qualificada ${ }^{(2-4)}$.

Diante de uma emergência clínica, é necessário o manejo correto do paciente por uma equipe treinada e preparada. Profissionais capacitados são cruciais, para que as manobras de reanimação sejam realizadas de forma precoce e eficaz, buscando a manutenção artificial do fluxo arterial para o cérebro e para outros órgãos vitais até que a circulação espontânea seja recuperada ${ }^{(5)}$. 
Diante disso, os enfermeiros são elementos fundamentais para identificar tal ocorrência, visto que detêm o potencial de serem as principais testemunhas de eventos no âmbito hospitalar. Logo, possuem competência técnica, institucional e legal para iniciar os procedimentos de $\mathrm{RCP}^{(6)}$. Ademais, durante o evento, podem comandar as etapas de reanimação, atuar como administradores, coordenadores, educadores do processo de treinamento das técnicas e como pontes entre as equipes multiprofissionais, de modo que a assistência seja realizada de forma ágil, sincronizada e eficiente, maximizando a qualidade do atendimento $^{(7)}$.

É importante ressaltar que é papel do profissional de enfermagem coordenar as ações e direcionar sua equipe, agindo nas mais diversas funções, como na instalação do desfibrilador externo automático (DEA), na administração de medicamentos, contagem de tempo, ventilações e compressões, além de ser de sua competência abrir caminhos nos quais sua equipe possa aperfeiçoar-se e, assim, realizar atendimentos com excelência $^{(8)}$.

Destaca-se que, para viabilizar uma assistência de qualidade pautada em protocolos atualizados, é indispensável que o enfermeiro aprimore suas habilidades cognitivas e motoras por meio de capacitações pautadas em evidências científicas, desde o percurso de sua formação acadêmica. Dessa forma, considerando o exposto, ressalta-se a importância de o acadêmico de enfermagem estar diante de manobras de RCP, visto que, como futuro enfermeiro, deverá possuir a capacidade de identificar precocemente os agravos e reduzir as taxas de mortalidade relacionadas ao evento, bem como as sequelas que, porventura, o paciente desenvolva devido à privação prolongada do oxigênio.

Diante do exposto, questiona-se: Qual o nível de conhecimento dos discentes de enfermagem acerca do reconhecimento da PCR e das manobras da RCP? Para responder tal questionamento, o presente estudo tem como objetivo avaliar o conhecimento de estudantes de enfermagem sobre o atendimento ao paciente em parada cardiorrespiratória.

\section{Método}

Trata-se de um estudo transversal e descritivo, com abordagem quantitativa, desenvolvido com estudantes do curso de enfermagem de uma instituição de ensino superior privada do município de João Pessoa, Paraíba, Brasil. A coleta de dados foi realizada no período entre junho e agosto de 2020.

A população do estudo compreendeu todos os estudantes do curso de enfermagem que estavam cursando o sexto, sétimo e oitavo períodos, totalizando 196 alunos. Foram incluídos, os indivíduos de ambos os sexos, com idade igual ou superior a 18 anos e que cursaram a disciplina de primeiros socorros e/ou unidades complexas. Os discentes que haviam trancado o curso ou estavam em licença médica durante a coleta das informações foram excluídos do estudo

A determinação da amostra foi do tipo probabilística, por meio da técnica de amostragem simples. Delimitou-se, considerando a seguinte fórmula: $\mathrm{n}=\mathrm{Z} 2 \mathrm{PQ} / \mathrm{d} 2$, sendo $\mathrm{n}=$ tamanho amostral mínimo; $\mathrm{Z}=$ =variável reduzida; $\mathrm{P}=$ probabilidade de encontrar o fenômeno estudado; $\mathrm{Q}=1-\mathrm{P} ; \mathrm{d}=$ precisão desejada. Adotou-se $\mathrm{p}=50 \%$ e parâmetro de erro amostral de 5\%. Após os devidos cálculos, a amostragem mínima definida foi composta por 130 discentes. Durante o período de coleta de dados, foram abordados 150 estudantes, dentre os quais 14 recusaram-se a participar. Após os esclarecimentos sobre os objetivos do estudo, aqueles que concordaram em contribuir com a pesquisa receberam o questionário pelo endereço eletrônico. Dessa forma, a amostra foi composta por 136 estudantes.

A coleta de dados deu-se por meio de um questionário construído na plataforma Formulários Google e divulgado on-line, por meio de aplicativos e redes sociais. O instrumento utilizado foi criado e validado por Bellan e Araujo ${ }^{(9)}$, seguindo o protocolo da American Heart Association (AHA) de 2005. Devido às atualizações sobre a temática publicadas ao longo dos anos, as alternativas propostas no instrumento original foram adaptadas de acordo com os destaques da AHA divulgadas entre os anos 2015 e 
2018. Logo, foi composto por 29 questões, divididas em duas partes: a primeira, constituía o perfil sociodemográfico, com questões subjetivas e objetivas. A segunda, versava sobre o conhecimento apresentado pelos discentes em relação à PCR, conforme instrumento validado ${ }^{(9)}$.

As questões objetivas apresentavam uma ou mais respostas corretas, com pesos diferentes, de acordo com o número de alternativas corretas. Dessa forma, as questões foram consideradas corretas, à medida que todas as informações mínimas foram assinaladas; parcialmente corretas, quando um ou mais conteúdos não foram destacados; e incorretas, quando nenhum dos conteúdos foram assinalados. Nas questões em que havia apenas uma alternativa correta, o entrevistado recebia o valor de um ponto. Entre aquelas que apresentavam mais de uma alternativa correta, dividiu-se o valor 1 pelo número de alternativas, determinando, dessa forma, o peso de cada questão, conforme as orientações das autoras. Logo, a estimativa de acertos foi obtida mediante a soma de todas as alternativas corretas.

Os dados foram codificados e armazenados no sistema computacional Statistical Package for the Social Sciences (SPSS), versão 20.0. A análise dos dados foi executada por meio de abordagem quantitativa e pela estatística descritiva de natureza univariada para todas as variáveis, incluindo medidas de frequência, posição e dispersão. Para verificar a normalidade dos dados, foi utilizado o teste de Kolmogorov Smirnov, que demonstrou que a variável dependente, média de questões acertadas, apresentava distribuição normal.

Logo, para identificar a correlação entre as variáveis, aplicou-se o Coeficiente de Correlação de Pearson. Com vistas a medir o grau de correlação, considerou-se que "r" variou de $+1 /-1$, para correlações positivas ou negativas. Quando evidenciado o valor de r=0 a correlação foi considerada nula. Para verificar a força de correlação considerou-se: 0 - ausência de correlação; 0 a 0,30 - correlação fraca; 0,30 a 0,70 - correlação moderada; >0,70 - correlação forte. Em todos os testes, considerou-se nível de significância de $5 \%{ }^{(10)}$. A fim de compreender a correlação entre a média de acertos e as questões em que se obteve maior conhecimento, realizou-se o referido teste.

Cabe destacar que, durante todo o processo da pesquisa, especialmente na fase da coleta de informações empíricas, foram observados os aspectos éticos que orientam a pesquisa envolvendo seres humanos, dispostos na Resolução $n^{\circ} 466 / 2012$ do Conselho Nacional de Saúde, especialmente o sigilo e a confidencialidade das informações $^{(11)}$. A pesquisa foi aprovada pelo Comitê de Ética e Pesquisa do Centro Universitário de João Pessoa, sob Parecer n 3 3.668.695/19.

\section{Resultados}

Constatou-se que, dos 136 acadêmicos de enfermagem que participaram do estudo, 89,7\% $(n=122)$ pertenciam ao sexo feminino, 85,3\% $(n=116)$ eram solteiros e 45,6\% $(n=62)$ cursavam o sétimo período. A idade variou entre 20 e 41 anos, com média de 23,79 anos (DP $\pm 4,52)$. Quanto ao conhecimento prévio sobre o assunto, 62,5\% $(n=85)$ afirmaram não ter cursado a disciplina de primeiros socorros, 100\% $(n=136)$ cursou a disciplina de unidades complexas, 66,2\% ( $n=90)$ não realizou treinamento em Suporte Básico de Vida (SBV), enquanto 83,8\% (n=114) não possuía aperfeiçoamento em Suporte Avançado de Vida (SAV), conforme observado na Tabela 1.

Tabela 1 - Distribuição das características sociodemográficas e acadêmicas dos estudantes de enfermagem. João Pessoa, Paraíba, Brasil - 2020. (N=136)

\begin{tabular}{l|cc}
\hline Variáveis & $\mathbf{n}$ & $\mathbf{\%}$ \\
\hline Sexo & & \\
Feminino & 122 & 89,7 \\
Masculino & 14 & 10,3 \\
Estado civil & & \\
Solteiro & 116 & 85,3 \\
Casada & 19 & 14,0 \\
Divorciada & 1 & 0,7
\end{tabular}


Tabela 1 - Distribuição das características sociodemográficas e acadêmicas dos estudantes de enfermagem. João Pessoa, Paraíba, Brasil - 2020. (N=136)

\begin{tabular}{lcc}
\hline Variáveis & n & \% \\
\hline Período acadêmico & 40 & 29,4 \\
$\quad$ Sexto & 62 & 45,6 \\
Sétimo & 34 & 25,0 \\
Oitavo & 65 \\
Cursou a disciplina de primeiros socorros & 62,5 \\
Não & 51 \\
Sim & 37,5 \\
Cursou a disciplina de unidades complexas & - \\
Não & 136 & - \\
Sim & 100 \\
Cursou aperfeiçoamento em Suporte Básico de Vida (SBV) & 60 \\
Não & 66,2 \\
Sim & 46 \\
Cursou aperfeiçoamento em Suporte Avançado de Vida (SAV) & 33,8 \\
Não & 114 \\
Sim & 22 & 83,8 \\
\hline
\end{tabular}

Fonte: Elaboração própria.

Nota: Sinal convencional utilizado:

- Dado numérico igual a zero não resultante de arredondamento.

Os discentes foram questionados acerca do nível de conhecimento sobre os protocolos de suporte básico e avançado de vida por meio de uma escala numérica, em que zero denotaria ausência de conhecimento e dez, a pontuação máxima. Diante disso, foi observado que os alunos apresentaram nota mínima três e máxima dez nesse quesito, com média de 7,74 (DP₫1,41). Ao verificar as questões que obtiveram maior número de erro, identificou-se deficiência nas perguntas a respeito das vias de administração da droga, dentre as quais, a maioria dos entrevistados elencou as vias intratraqueal $(n=111$; $81,6 \%)$ e via intraóssea $(n=112 ; 82,4 \%)$ como melhor escolha, em detrimento das vias endovenosa periférica $(n=107 ; 78,7 \%)$ e acesso venoso central $(n=45 ; 33,1 \%)$.

Ainda em relação à medicação, 126 (92,6\%) participantes assinalaram adrenalina como droga a ser utilizada em casos de parada cardiorrespiratória; 97 (71,3\%), amiodarona; e 32 (27,9\%) elencaram a lidocaína. Ademais, a despeito dos ritmos cardíacos, 108 (79,4\%) indicaram que a TVSP é considerada um ritmo de parada, $92(67,6 \%)$ sinalizaram a fibrilação ventricular, $86(63,2 \%)$ identificaram a AESP e 85 (62,2\%), assistolia.

Os dados relativos ao conhecimento teórico dos discentes sobre PCR e RCP estão apresentados na Tabela 2.

Tabela 2 - Distribuição das respostas dos discentes sobre o conhecimento teórico em Parada Cardiorrespiratória/Ressuscitação cardiopulmonar. João Pessoa, Paraíba, Brasil - 2020. (N=136)

(continua)

\begin{tabular}{l|c|c|c|c|c|c}
\hline \multirow{2}{*}{ Variáveis } & \multicolumn{9}{c}{ Respostas } \\
\cline { 2 - 7 } & \multicolumn{2}{|c|}{ Corretas } & \multicolumn{1}{c}{ Parcialmente corretas } & \multicolumn{2}{c}{ Incorretas } \\
\cline { 2 - 7 } & $\mathbf{n}$ & $\mathbf{0}$ & $\mathbf{n}$ & $\mathbf{\%}$ & $\mathbf{n}$ & $\mathbf{\%}$ \\
\hline Definição de Parada & 133 & 97,8 & - & - & 3 & 2,2 \\
Cardiorrespiratória (PCR) & & & & & - & - \\
Reconhecimento da PCR & 46 & 33,8 & 90 & 66,2 & 62 & 45,6 \\
Conduta imediata & 3 & 2,2 & 71 & 52,2 & 62 & 4,4 \\
Ritmos cardíacos de PCR & 67 & 49,3 & 63 & 46,3 & 6 & 30,1 \\
Ritmos cardíacos chocáveis & 79 & 58,1 & 16 & 11,8 & 41 &
\end{tabular}


Tabela 2 - Distribuição das respostas dos discentes sobre o conhecimento teórico em Parada Cardiorrespiratória/Ressuscitação cardiopulmonar. João Pessoa, Paraỉba, Brasil - 2020. (N=136) (conclusão)

\begin{tabular}{|c|c|c|c|c|c|c|}
\hline \multirow{3}{*}{ Variáveis } & \multicolumn{6}{|c|}{ Respostas } \\
\hline & \multicolumn{2}{|c|}{ Corretas } & \multicolumn{2}{|c|}{ Parcialmente corretas } & \multicolumn{2}{|c|}{ Incorretas } \\
\hline & $\mathbf{n}$ & $\%$ & $\mathbf{n}$ & $\%$ & $\mathbf{n}$ & $\%$ \\
\hline $\begin{array}{l}\text { Em que consiste Suporte Básico de } \\
\text { Vida (SBV) }\end{array}$ & 17 & 12,5 & 118 & 86,8 & 1 & 0,7 \\
\hline $\begin{array}{l}\text { Em que consiste Suporte Avançado } \\
\text { de Vida (SAV) }\end{array}$ & 22 & 16,2 & 111 & 81,6 & 3 & 2,2 \\
\hline Ventilar paciente intubado & 62 & 45,6 & - & - & 74 & 54,4 \\
\hline Ventilar paciente não intubado & 117 & 86,9 & - & - & 19 & 14,0 \\
\hline Postura para Compressões & 30 & 22,1 & 95 & 69,9 & 11 & 8,1 \\
\hline Torácicas Externas (CTE) & & & & & & \\
\hline Profundidade das compressões & 16 & 11,8 & 81 & 59,6 & 39 & 28,7 \\
\hline $\begin{array}{l}\text { Carga inicial desfibrilador externo } \\
\text { automático (DEA) }\end{array}$ & 99 & 72,8 & - & - & 37 & 27,2 \\
\hline Carga máxima DEA & 92 & 67,6 & - & - & 44 & 32,4 \\
\hline Vias de administração de fármacos & 20 & 14,7 & 75 & 55,1 & 41 & 30,1 \\
\hline Fármacos utilizados & 34 & 25,0 & 99 & 72,8 & 3 & 2,2 \\
\hline Composição PCR & 99 & 72,8 & - & - & 37 & 27,2 \\
\hline
\end{tabular}

Fonte: Elaboração própria.

Nota: Sinal convencional utilizado:

- Dado numérico igual a zero não resultante de arredondamento.

Após realização do teste de Correlação de Pearson, observou-se correlação estatisticamente significativa, positiva e fraca $(r=0,29 ; p=0,001)$ entre a média de acertos e o nível de conhecimento autorreferido. Verificou-se também correlação positiva e estatisticamente significativa entre a média total de acertos e as médias de respostas corretas nas seguintes variáveis: identificação dos ritmos chocáveis, descrição das características que determinam as diferenças entre o SBV e SAV, suporte ventilatório em pacientes não intubados, assim como as vias de administração das drogas (Tabela 3).

Tabela 3 - Correlação média de acertos e médias de respostas corretas em diferentes variáveis por meio do Teste de Correlação de Pearson. João Pessoa, Paraíba, Brasil - 2020. (N=136)

\begin{tabular}{l|c|c}
\hline \multirow{2}{*}{ Variável } & \multicolumn{2}{|c}{ Média de acertos } \\
\cline { 2 - 3 } & $\begin{array}{c}\text { Coeficiente de correlação de } \\
\text { Pearson (r) }\end{array}$ & p-valor \\
\hline Identificação dos ritmos chocáveis & 0,17 & 0,004 \\
Em que consiste o Suporte Básico de Vida (SBV) & 0,28 & 0,011 \\
Em que consiste o Suporte Avançado de Vida (SAV) & 0,22 & 0,012 \\
Ventilação em pacientes não intubados & 0,28 & 0,001 \\
Via de administração das drogas & 0,34 & 0,001 \\
\hline
\end{tabular}

Fonte: Elaboração própria.

Ao analisar a média de acertos, identificou-se que os homens apresentaram um índice de acertos maior, se comparados às mulheres $(p=0,005)$. Em relação à obtenção do conhecimento, evidenciou-se que a média de acertos entre os estudantes que cursaram a disciplina de primeiros socorros era maior $(p=0,012)$, enquanto a realização de cursos extracurriculares não impactou de forma significativa entre os participantes da presente pesquisa (Tabela 4). 
Tabela 4 - Características da amostra conforme a média de conhecimento sobre as condutas frente a uma Parada Cardiorrespiratória por meio do T-Student. João Pessoa, Paraíba, Brasil - 2020. (N=136)

\begin{tabular}{|c|c|c|c|}
\hline Variáveis & Média & Desvio Padrão & p-valor \\
\hline Sexo & & & $0,005^{*}$ \\
\hline Feminino & 10,93 & $\pm 2,50$ & \\
\hline Masculino & 11,35 & $\pm 1,35$ & \\
\hline Cursou disciplina de primeiros socorros & & & $0,012^{*}$ \\
\hline $\operatorname{Sim}$ & 11,81 & $\pm 2,23$ & \\
\hline Não & 10,72 & $\pm 2,54$ & \\
\hline Realizou curso de Suporte Básico de Vida (SBV) & & & 0,072 \\
\hline Sim & 11,65 & $\pm 2,61$ & \\
\hline Não & 10,88 & \pm 2.32 & \\
\hline Realizou curso de Suporte Avançado de Vida (SAV) & & & 0,849 \\
\hline Sim & 11,24 & $\pm 2,78$ & \\
\hline Não & 11,11 & \pm 2.43 & \\
\hline
\end{tabular}

Fonte: Elaboração própria.

* Resultado Estatisticamente Significativo.

\section{Discussão}

É admitido que a efetividade no atendimento às vítimas de PCR está diretamente associada ao reconhecimento precoce e à pronta realização das manobras de ressuscitação cardiopulmonar. Destaca-se que a taxa de sobrevivência de uma parada cardiopulmonar assistida é de aproximadamente 49\%, dependendo do ritmo cardíaco e das manobras de resgate precoce. Logo, o conhecimento sobre os ritmos, as drogas que podem ser administradas, bem como as vias de administração fortalecem a equipe de saúde e aumentam as chances de o procedimento ser bem-sucedido ${ }^{(12)}$.

Em relação aos dados sociodemográficos, verificou-se que a maioria dos estudantes cursavam o sétimo período e pertenciam ao sexo feminino, com idade entre 20 e 41 anos. Historicamente, é reconhecido que as práticas do cuidar estão associadas ao sexo feminino, conforme evidenciado em estudo realizado com acadêmicos de enfermagem de uma universidade privada da região de Florianópolis (SC), em que a maioria eram mulheres, com idade entre 22 e 49 anos, matriculadas no último período do curso de graduação $^{(13)}$.

Sobre reconhecimento da PCR, segundo O protocolo da $\mathrm{AHA}^{(14)}$, ao observar um indivíduo imóvel, deve-se checar a responsividade, observar se há ausência de respiração ou apenas gasping e também verificar se há inexistência de pulso carotídeo. Os resultados da pesquisa apontam que não houve respostas incorretas diante dos sinais encontrados na parada, porém $66,2 \%$ responderam de forma parcialmente correta, deixando de marcar a ausência de consciência como um dos sinais da parada cardíaca.

É reconhecido que a inconsciência pode ser causada por várias situações clínicas distintas, como, por exemplo, arritmias e obstrução das artérias coronárias ou pulmonares. Tais condições interferem na hematose, culminam com a diminuição de oxigênio na corrente sanguínea e contribuem posteriormente com a hipóxia celular. A redução do aporte de oxigênio no tecido cerebral pode suscitar o rebaixamento do nível de consciência e episódios de desmaio ${ }^{(15)}$.

Junto com as compressões cardíacas, O manejo da via respiratória constitui uma intervenção importante para a manutenção da vida do indivíduo em PCR. Em relação à via aérea avançada, a pesquisa mostra que 54,4\% responderam de forma incorreta, ao marcarem a opção que a conduta adequada a ser realizada em pacientes com via aérea avançada seria mantê-los conectados ao ventilador mecânico e aumentar a FiO2 (fração inspirada de oxigênio) para 100\%, 
ofertando o máximo de oxigênio possível durante a RCP.

De acordo com a Sociedade Brasileira de Cardiologia ${ }^{(16)}$, durante a RCP em pacientes com via aérea avançada, as ventilações devem ser administradas utilizando-se a bolsa válvula máscara (BVM), de modo assíncrono com as compressões torácicas. Para tanto, recomenda-se o aumento da FiO2 para 100\%, a fim de garantir o aumento da oxi-hemoglobina arterial e a oferta de oxigênio. Logo, conforme os protocolos, recomenda-se administrar uma ventilação a cada seis segundos, totalizando 10 ventilações por minuto.

É indiscutível a importância da desfibrilação precoce na manutenção do elo de sobrevivência. Observou-se, no presente estudo, que a maioria dos participantes responderam corretamente qual seria a carga inicial ofertada ao paciente em PCR, enquanto 32,4\% não conheciam a carga máxima, em joules, que poderia ser administrada. O desfibrilador consiste em um equipamento que fornece cargas elétricas e pode ser utilizado para reverter algumas arritmias, a exemplo da TVSP e FV, ambas evidenciadas em parada cardiorrespiratória. A carga inicial ofertada é de 120 joules e a máxima é de 200 joules em aparelho bifásico. Já em monofásicos, a carga mínima é de 200 joules e a carga máxima é de 360 joules, podendo variar de acordo com as especificações do fabricante ${ }^{(17)}$.

Ao analisar o nível de conhecimento dos discentes acerca dos protocolos de SBV e SAV, identificou-se que 55,1\% deles responderam de forma parcialmente correta as questões relativas à administração das drogas, sobretudo no reconhecimento do acesso venoso central como via de administração dos fármacos. É oportuno destacar que as primeiras vias de escolha são a endovenosa periférica e central. Se, por alguma hipótese, os acessos vasculares não forem conseguidos, pode-se optar pela via intraóssea ou endotraqueal (administrando drogas lipossolúveis), na qual será utilizado o dobro da quantidade de medicação ${ }^{(16)}$.

Além das vias de administração, verificou-se que os alunos responderam de forma parcialmente correta sobre as medicações que devem ser adotadas frente a uma PCR, já que poucos discentes assinalaram a lidocaína como uma alternativa de fármaco, droga recomendada pela AHA no ano de 2018. É oportuno destacar que são utilizados dois tipos de drogas: o vasopressor epinefrina, que servirá para aumentar a pressão de perfusão coronariana durante a RCP; e os antiarrítmicos, como a amiodarona ou lidocaína $^{(16)}$.

Entretanto, a administração desses medicamentos exige o conhecimento sobre os ritmos cardíacos que precedem uma PCR, como TVSP, FV, AESP e assistolia ${ }^{(17)}$. Neste estudo, a quase metade dos participantes responderam corretamente essa questão, havendo apenas 4,4\% de respostas incorretas. Este resultado vai de encontro a pesquisa semelhante, na qual apenas 2,1\% responderam corretamente os ritmos cardíacos evidenciados em uma parada cardiorrespiratória ${ }^{(18)}$.

O conhecimento sobre os ritmos cardíacos é essencial para a compreensão das condutas que devem ser estabelecidas. Diante da TVSP e $\mathrm{FV}$, denominados de ritmos chocáveis, poderá ser administrado epinefrina, amiodarona ou lidocaína, enquanto que, na vigência da AESP e assistolia, os antiarrítmicos não são indicados ${ }^{(17)}$. No presente estudo, verificou-se que 58,1\% responderam de forma correta, diferente do que ocorreu em pesquisa semelhante, na qual apenas $27,3 \%$ dos discentes reconheceram a diferença entre os ritmos cardíacos ${ }^{(19)}$.

Os primeiros socorros são técnicas utilizadas para assistir as vítimas que necessitam de ajuda imediata, com objetivo de evitar consequências fatais, por falta de assistência, e manter os sinais vitais até a chegada da equipe de saúde especializada. Neste sentido, uma pessoa que obtém treinamento acerca dos procedimentos, poderá socorrer a família, amigos, colegas de trabalho ou até mesmo desconhecidos, caso exista algum problema que esteja lhe afetando no momento. Logo, adquirir conhecimentos básicos em primeiros socorros poderá salvar vidas ${ }^{(20)}$.

O conhecimento teórico é importante para reconhecer as necessidades da vítima, contudo o desenvolvimento de habilidades práticas 
é fundamental para adquirir confiança em si mesmo e conquistar autonomia ${ }^{(21)}$. Ademais, é de suma importância manter-se atualizado, para realizar as técnicas de segurança de maneira adequada e garantir eficiência no atendimento às vítimas. Estudo ${ }^{(22)}$ desenvolvido em Portugal sobre o conhecimento da população acerca do SBV corrobora essa assertiva. A referida pesquisa demonstrou que há necessidade de capacitação de leigos para reduzir a taxa de mortalidade e morbidade em situações de acidentes e doenças súbitas em cenário extra-hospitalar, visto que vítimas que receberam assistência de algum cidadão com treinamento apresentaram chance de sobreviver quatro vezes mais.

Portanto, conforme o estudo ${ }^{(23)}$, a educação continuada em primeiros socorros tende a ser relevante frente ao aumento da ocorrência de urgência/emergência, mostrando ainda a necessidade de este assunto ser de domínio público, tendo em vista que exige ações imediatas e qualificadas. Diante disso, é preciso mostrar à população a importância desse assunto e a necessidade de aprimoramento sobre o tema.

Os discentes de enfermagem devem possuir domínio teórico e prático acerca das manobras de ressuscitação cardiopulmonar, visto que o enfermeiro, além de assistir o paciente em quadros de emergência, é um agente educador, atuando na oferta de treinamentos à população. Além disso, ao manter o conhecimento sempre atualizado em sua área de atuação, poderá proporcionar melhor atendimento e bem-estar ao seu cliente.

Como limitação do estudo, destaca-se que, por ter sido realizado virtualmente em decorrência da pandemia, devido ao novo coronavírus, alguns alunos tiveram contato apenas com o conteúdo teórico, observando, assim, a necessidade e importância de praticar o tema administrado. Considerando isso, é de suma importância que os acadêmicos aperfeiçoem-se sobre os protocolos estabelecidos frente a uma PCR. Ressalta-se também a importância de os docentes criarem estratégias ou metodologias que facilitem a aprendizagem desse assunto, envolvendo todas as etapas, devido à sua importância. Além disso, seria igualmente importante se as instituições de ensino pudessem promover eventos, minicursos, rodas de conversas, entre outros recursos, a fim de fortalecer a formação de futuros enfermeiros.

\section{Conclusão}

A pesquisa revelou que, de maneira geral, os discentes que possuíam um bom nível de compreensão em relação aos protocolos relacionados ao atendimento ao paciente em parada cardiorrespiratória foram aqueles que cursaram disciplina de primeiros socorros. Contudo, é oportuno destacar que eles apresentaram dificuldades para acompanhar as atualizações dos protocolos de suporte básico e avançado de vida relacionados à parada cardiorrespiratória.

\section{Colaborações:}

1 - concepção, projeto, análise e interpretação dos dados: Felipe Pereira Nunes e Keylla Talitha Fernandes Barbosa;

2 - redação do artigo e revisão crítica relevante do conteúdo intelectual: Felipe Pereira Nunes, Keylla Talitha Fernandes Barbosa, Vinícius de Morais Santos, Lucianna Jéssica Araújo da Silva e Júlia Beatriz Lacet Nóbrega da Silva;

3 - aprovação final da versão a ser publicada: Fabiana Maria Rodrigues Lopes de Oliveira e Natalia Pessoa da Rocha Leal.

\section{Referências}

1. Citolino Filho CM, Santos ES, Silva RCG, Nogueira LS. Factors affecting the quality of cardiopulmonary resuscitation in inpatient units: perception of nurses. Rev esc enferm USP. 2015;49(6):907-13. DOI:10.1590/S0080-6234 20150000600005

2. Moura JG, Brito MPS, Rocha GOS, Moura LTR. The Knowledge and Acting of a Nursing Team from a Sector of Cardiorespiratory Arrest Urgent Care. J res: fundam care Online. 2019;11(3):634-40. DOI:10.9789/2175-5361.2019.v11i3.634-640

3. Myerbur RJ, Castellanos A. Parada Cardíaca e Morte Súbita Cardíaca: Parada Cardíaca. In: Bonow RO, Mann DL, Zipes DP, Libby $P$. 
Braunwald: Tratado de Doenças Cardiovasculares. 10a ed. Rio de Janeiro: Elsevier; 2017. p. 858-912.

4. Barbosa ISL, Moraes-Filho IM, Pereira BA, Soares SR, Silva W, Santos OP. O conhecimento do profissional de enfermagem frente à parada cardiorrespiratória segundo as novas diretrizes e suas atualizações. Rev Cient Sena Aires [Internet]. 2018 [cited 2021 Feb 19];7(2):117-26. Available from: http://revistafacesa.senaaires.com.br/index. $\mathrm{php} / \mathrm{revisa} /$ article/view/311

5. Espíndola MCM, Espíndola MMM, Moura LTR, Lacerda LCA. Cardiorespiratory arrest: knowledge of nursing professionals in an intensive therapy unit. J Nurs UFPE on line. 2017;11(7):2773-8. DOI: 10.5205/reuol.10939-97553-1-RV.1107201717

6. Pulze G, Alves WS, Paiva BC, Ferretti-Rebustini REL. Incidência e Fatores Associados à Parada Cardiorrespiratória nas Primeiras 24 Horas de Internação em Unidades de Terapia Intensiva. Rev Soc Cardiol Estado de São Paulo [Internet]. 2019 [cited 2021 Feb 19];29(2):192-6. Available from: http://socesp.org.br/revista/ edicao-atual/incidencia-e-fatores-associadosa-parada-cardiorrespiratoria-nas-primeiras-24horas-de-internacao-em-unidades-de-terapiaintensiva/104/708/

7. Pereira DS, Vieira AKI, Ferreira AM, Bezerra AMF, Bezerra WKT. Atuação do Enfermeiro Frente à Parada Cardiorrespiratória (PCR). Rev Bras Educ Saúde [Internet]. 2015 [cited 2021 Feb 19];5(3):8-17. Available from: https:// www.gvaa.com.br/revista/index.php/REBES/ article/view/3583

8. Carvalho ASA, Santos FF, Viana ER. Atuação e liderança do enfermeiro frente à parada cardiorespiratória na unidade de terapia intensiva. Persp Online: biol \& saúde. 2015;5(18):30-1. DOI: 10.25242/88685182015765

9. Bellan MC, Araújo IEM. Capacitação do enfermeiro para o atendimento da parada cardiorrespiratória [dissertação]. [Internet]. Campinas (SP): Universidade Estadual de Campinas. Faculdade de Ciências Médicas; 2006 [cited 2021 Feb 19]. Available from: http://repositorio. unicamp.br/jspui/handle/REPOSIP/309773

10. Akoglu H. User's guide to correlation coefficients. Turk J Emerg Med. 2018;18(3): 91-3. DOI: https://doi.org/10.1016/j.tjem.2018. 08.001

11. Brasil. Ministério da Saúde. Resolução no 466, de 12 de dezembro de 2012. Aprova as diretrizes e normas regulamentadoras de pesquisas envolvendo seres humanos [Internet]. Brasília (DF); 2012 [cited 2021 Feb 13]. Available from: https://bvsms.saude.gov.br/bvs/saudelegis/ cns/2013/res0466_12_12_2012.html

12. Freire ILS, Santos FR, Nascimento ACS, Medeiros AB, Silva BCO, Cavalcante CAA. Validation of Questionnaire for the Evaluation of Knowledge of Nursing Teachers and Students on the Basic Life Support. J Nurs UFPE on line. 2017;11(12):4953-60. DOI: https://doi.org/10.5205/1981-8963-v11i12a 23556p4953-4960-2017

13. Moraes CL, Vasconcelos PC, Souza EA, Bellaguarda MLR. Cardiopulmonar knowledge of nursing academics on cardiopulmonary rehability. Rev Enf Centro-Oeste Mineiro. 2017;7: e1779. DOI: 10.19175/recom.v7i0.1779

14. American Heart Association. Destaques da American Heart Association: diretrizes de RCP e ACE. Dallas; 2015.

15. Prestes JN, Menetrier JV. Conhecimento da equipe de enfermagem de uma unidade de terapia intensiva adulta sobre a parada cardiorrespiratória. Biosaúde [Internet]. 2017 [cited 2021 Feb 19];19(1):1-11. Available from: http://www.uel.br/revistas/uel/index.php/ biosaude/article/view/27905

16. Sociedade Brasileira de Cardiologia. Atualização da Diretriz de Ressuscitação Cardiopulmonar e Cuidados Cardiovasculares de Emergência da Sociedade Brasileira de Cardiologia. Arq Bras Cardiol [Internet] 2019 [cited 2021 Feb 19];113:449-663. Available from: http:// publicacoes.cardiol.br/portal/abc/portugues/ 2019/v11303/atualizacao-da-diretriz-deressuscitacao-cardiopulmonar-e-cuidadoscardiovasculares-de-emergencia-da-sociedadebrasileira-de-cardiologia-2019.asp

17. American Heart Association. Destaques das Atualizações Focadas em Recomendações de 2018 da American Heart Association para RCP e ACE: Suporte Avançado de Vida Cardiovascular e Suporte Avançado de Vida em Pediatria. Dallas; 2018.

18. Gonzalez CM, Ferreira N, Nunes NAH. Entendimento de graduandos em enfermagem acerca do seu papel na assistência a parada cardiorrespiratória. Rev enferm UFPE on line. 2016;10(6):2038-42. DOI: 10.5205/1981-8963-v10i 6a11215p2038-2042-2016 
Felipe Pereira Nunes, Keylla Talitha Fernandes Barbosa, Fabiana Maria Rodrigues Lopes de Oliveira, Natalia Pessoa da Rocha Leal, Vinícius de Morais Santos, Lucianna Jéssica Araújo da Silva, Júlia Beatriz Lacet Nóbrega da Silva

19. Resende RT, Barbosa ACS, Silva Luiz F, Santos KB, Frank DBP, Motta DS, et al. Conhecimento dos Acadêmicos de Enfermagem sobre Suporte Básico de Vida. Rev enferm UFPE on line. 2019;13(5):1231-6. DOI: 10.5205/19818963-v13i05a238984p1231-1236-2019

20. Ragadali Filho A, Pereira NA, Leal I, Anjos QS, Loose JTT. A importância do treinamento de primeiros socorros no trabalho. Rev Saberes [Internet]. 2015 [cited 2021 Feb 19];3(2):114-25. Available from: https://facsaopaulo.edu.br/wpcontent/uploads/sites/16/2018/05/ed3/10.pdf

21. Saldanha MFLS, Silva A, Fernandes AO, Filoni E. Avaliação do conhecimento de universitários sobre os sinais e sintomas e primeiros socorros em parada cardiorrespiratória.
Rev Bras Educ Saúde. 2016;6(1):8-14. DOI: 10.18378/rebes.v6i1.3823

22. Dixe MACR, Gomes JCR. Knowledge of the Portuguese population on Basic Life Support and availability to attend training. Rev esc enferm USP. 2015;49(4):636-44. DOI: 10.1590/ S0080-623420150000400015

23. Oliveira MR, Leonel ARA, Montezeli JH, Gastaldi AB, Martins EAP, Caveião C. Conception of undergraduate nursing students on the practice of health education on first aid. Rev Rene. 2015;16(2):150-8. DOI: 10.15253/2175-6783.2015000200003

Recebido: 26 de janeiro 2021 Aprovado: 28 de junho de 2021

Publicado: 12 de agosto de 2021

A Revista Baiana de Enfermagem utiliza a Licença Creative Commons - Atribuição-NãoComercial 4.0 Internacional. https://creativecommons.org/licenses/by-nc/4.0/ Este artigo é de acesso aberto distribuído sob os termos da Licença Creative Commons (CC BY-NC). Esta licença permite que outros remixem, adaptem e criem a partir do seu trabalho para fins não comerciais. Embora os novos trabalhos tenham de lhe atribuir o devido crédito e não possam ser usados para fins comerciais, os usuários não têm de licenciar esses trabalhos derivados sob os mesmos termos. 